\title{
Intercultural Adaptation Process and Its Determinants
}

\author{
Renata Čuhlová \\ Czech Research Centre, Zhejiang Financial College, Hangzhou, China
}

\section{Email address:}

renata.cuhlova@gmail.com

\section{To cite this article:}

Renata Čuhlová. Intercultural Adaptation Process and Its Determinants. International Journal of Economics, Finance and Management Sciences. Vol. 7, No. 6, 2019, pp. 215-221. doi: 10.11648/j.ijefm.20190706.16

Received: November 23 2019; Accepted: December 9, 2019; Published: December 12, 2019

\begin{abstract}
The increasing trend of international mobility has intensified intercultural communication and expanded the requirements expected from international managers. The whole expatriation process represents a costly matter for the engaged companies. Detecting determinants of the intercultural adaptation can significantly minimaze the risk of failure during the foreign assignment. Moreover, the consideration should already be given in the beginning when the selection of eligible candidates for expatriation is done. The research objective of the paper is to investigate the determinants of intercultural adaptation of expatriates with international assignment experience and consequently to understand the complexity of the adaptation process while working abroad. Firstly, theoretical background reviews previous studies on adaptation process and cultural distance, intercultural competences and motivation as important factors. Next, primary data were obtained from Czech expatriates via questionnaire regardless the country of their foreign assignment. Additionally, the final model of intercultural adaptation was developed by applying a systematic thinking approach as an appropriate method emphasizing links and backward dynamics between the elements. The model is based on interaction of six determinants; such as: intercultural competences, language skills, intercultural training, past intercultural experience, motivation and cultural distance; that were identified from primary and secondary research as the most crucial variables. The findings lead to deeper understanding of the processes and help to improve the selection process of suitable candidate for foreign assignment and the intercultural training in order to reach higher level of adjustment.
\end{abstract}

Keywords: Cultural Differences, Cultural Distance, Expatriation, Intercultural Communication, International Business

\section{Introduction}

Globalization has led to increasing international mobility and migration flows, also due to the expansion of multinational corporations. There is more frequent professional contact between people from different cultures and thus more obvious manifestations of cultural distances. Culture generally shapes the most basic assumptions we have regarding the respective rights and responsibilities and so cultural differences between the parties may increase the risk of misunderstandings. In order to successfully work in intercultural environment, culture specifics must be recognized, respected, and reconciled.

Multinational companies play an important role in the economies of most countries and in international economic relations. Through direct foreign investment or other numerous ways, they can bring substantial benefits to the home and host countries. They also create potential to make more efficient use of capital, to increase economic and social well-being, to meet basic needs through both direct and indirect job creation. These trends make the traditional composition of branches of multinational companies and internationally operating companies more and more diversified and the expatriation has become a common strategy of multinational enterprises to internationalize its businesses.

Cultural diversity in the workplace can bring many benefits. The company has the opportunity to use various combinations of human resources that can bring non-standard management and development solutions. Internationally experienced talented individuals can be a key source of competitive advantage in the domestic and foreign markets. The importance of presented research topic reflects the high financial demand of this corporate process, as relocating 
employees abroad is. It is the reason is why the intercultural adaptation process and its individual determinants are crucial to investigate and understand.

The paper is structured as follows: firstly, the literature review provides the theoretical foundation of adaptation process and its models including the key factors influencing the adaptation; second part describes the methodology used in the paper and gives data on respondents of the questionnaire. The paper continues with discussion of findings, including presentation of model of intercultural adaptation created based on the combination of previous studies and primary research.

\section{Theoretical Background}

\subsection{Adaptation Process}

The adaptation means a continuous dynamic process in which an individual is confronted with subjectively new demands and demands gained by acculturation that are placed on him within the new cultural environment. At the same time, values and attitudes of adapting individuals may change $[1,2]$. Adaptation is at the very end of the process of psychological acculturation, which represents the changes that result from an individual's contact with another cultural group [1]. According to the general theory of work adaptation, work adaptation is achieved when the employee is satisfied with the work environment. The degree of intercultural adjustment to the new environment affects the work performance of the posted employee [3].

The adaptation process of expatriates generally proceeds in a certain standard manner, which can be illustrated by the Lysgaard U-curve [4]. Initial positive feelings of enthusiasm for the new environment (the so-called honeymoon) are usually replaced after a few weeks by a phase of cultural shock, which is manifested by disorientation, confusion and depression. When entering a new country, these feelings happen due to the disagreement of existing behavioral standards with those recognized in the new country, and confusion arises in the context of role expectations, when roles and expectations associated with them are suddenly changed [5].

Symptoms of cultural shock in an individual can range from mild emotional disorders to severe psychoses. Some authors [1] favor the term acculturative stress which is perceived as better description of the cultures interaction context. The intensity of the expatriate's response to the new cultural environment is determined by the type and duration of the stress situation and, of course, by the individual's predispositions as some people tends to develop coping strategies for rapid adaptation much more easily [6]. The stage of cultural stress is followed by a stage of alienation from the host culture, in which hostility and the search for negative stereotypes occur. Functional and cultural adaptations are established only after several months since the beginning of assignment $[7,8]$.

The first phase of the developmental model is denial, when the culture itself is considered the only correct one and there is no realization of intercultural differences. The next stage is defense, where the individual rejects a foreign culture, tends to prejudice and stereotyping. The third phase is called minimization, an effort to avoid the differences of cultures, this phase being the last of the three ethnocentric, ie, culture-oriented, phases. The next three phases, called ethnorelative, indicate a form of acceptance of a foreign culture. This includes the acceptance phase, where cultural diversity is already accepted by the individual, but does not always mean the popularity of the other culture. This is followed by a phase of adaptation that occurs only after intensive contact with a foreign culture. The last stage is integration, where one can fully accept the identity of a new culture but the question is to what extent it will retain its own culture [9].

The W-curve [10] complements the U-curve with an additional "U", highlighting the expatriate's experience of returning home, the repatriation period and the phenomenon of reverse cultural shock. Previous studies [10,11] assume that even after returning, the expatriate first undergoes a reverse cultural shock, which can be defined as a "process of re-adaptation, acculturation and assimilation into an individual's home culture after spending more time. in a different culture" [10, pp. 83-84]. The main difference between reverse and classical cultural shock is in anticipation Expatriates (repatriates in this stage of the assignment process) often assume that they return to the same home environment as they left it but these expectations are often not fulfilled. While entering a foreign unknown environment, individuals and their surroundings assume a certain degree of cultural shock, but often no one counts on returning to their home country [8]. It is important to note here the crucial role of the HR department which often does not adequately prepare employees to become aware of changes after returning from assignment [12].

\subsection{Cultural Distance}

The culture distance represents the level of cultural difference between home and host country. This concept is a subject of studies concerning not only the attractiveness of foreign markets for migrants, but also for the multinational companies themselves deciding on and location of the way of entering the foreign market. Moreover, it has proved to be an important predictor of adaptation [13]. The specific cultural distance between country A and country B can be calculated by using various economic or psychological measures based on national cultural values frameworks [7, 14]. Cultural distance and intercultural adaptation are interrelated. The greater difference between two cultures will be more challenging to adapt to [13].

\subsection{Intercultural Competences}

The concept of intercultural competence refers to the ability of an individual to adequately interact with persons from different cultural backgrounds and it plays an important role in influencing the individual's performance and cultural 
adaptation and hence the effectiveness of the expatriate's stay. The intercultural competences represent the consciousness, knowledge and skills that are necessary for effective work across ethnic and cultural differences of different groups [15].

The process of acquiring intercultural competences includes personality predispositions (such as self-reflection, empathy, cultural sensitivity, curiosity, self-confidence and reduced anxiety), intercultural confrontation, formation of intercultural experience, intercultural learning and intercultural understanding [16]. Competency improves communication efficiency, teamwork capabilities and task performance.

Studies show that the selection process itself, based on the abovementioned competencies, is not in itself a sufficient guarantee of the expatriate's success. Pre-departure training as well as ongoing support during the departure process, together with a proper selection of the right candidate, are combination for effective beginning of the foreign assignment.

\subsection{Motivation}

Finding out the motivation factors, as a predisposition for a successful foreign working stay, is becoming an increasingly important issue. Motivation is the basis for the enthusiasm and energy with which the expatriate enters the expatriation process and with what enthusiasm and effort he or she performs during the trip. By identifying these drivers of employee's motivation, the company can undoubtedly benefit.

Although salary and bonuses are naturally an important motive as they can increase an individual's personal status, these rewards are often the secondary factor and the core of motivation belong to a higher level of needs, as illustrated by the Maslow or Alderfer Pyramid of Needs [17, 18].

The expatriates can often be motivated by a variety of factors, depending on their specific situation. Therefore, although an exhaustive list of motives cannot be stated, a study [17] defines four main categories by which expatriates can be classified into following groups:

1. Explorer - individuals have an inner desire to live in a new culture and experience more than just as a tourist. Motives are also personal fulfillment and development.

2. Refugee - motivation to move abroad for work (both short and long-term) also includes the search for opportunities other than those available in the home country to improve personal and/or professional life.

3. Mercenary - individuals for whom financial reward is the main motive for accepting a foreign assignment.

4. Architect - the main motive is building career and the motives are clearly related to professional life.

The increasing attention to the motivation of assigned employees, bearing in mind varying importance of individual motivators across generations should be considered. For instance, in terms of the generation of the so-called millenials (born between 1980 and 2000), who are currently entering a phase of peak economic activity; changes in motivation factors can certainly be expected.

\section{Methodology}

The aim of the research was to investigate the experience of expatriates with intercultural training as an important part of the preparation for host culture and a method to ease the adaptation process.

The presented research was carried out in headquarter of a multinational company in Czechia. The company was chosen for its strategy, experiences and diversity that characterize the company's expatriation process. In terms of the Czech environment, there is not another organization with that number of assignments available for deduction of general conclusion on this topic.

Data for the presented study were extracted from an email questionnaire targeted at Czech expatriates assigned to work abroad [12]. The targeted sample was chosen based on criteria stated in the literature review [19] as well as consultations with the company. The sample of Czech expatriates consisted of current expatriates with experience of minimal 3 months already on assignment; and repatriates with maximal 6 months after return from assignment.

The sample was contacted regardless the host country of the assignment. A total of 302 Czech expatriates received the email questionnaire through the internal distribution system of the organization. The response rate was $54.3 \%$. Data were obtained from expatriates with experience in Germany, China, India, the United Kingdom, Russia, Slovakia, Spain, Poland and Malaysia.

The Statistica 13 and Statgraphics programs were used for statistical analysis. Both non-parametric tests Kruskal-Wallis test and Kendall test were selected based on the nature of the data obtained. The conclusions of the tests are based on a comparison with the significance level $\alpha=0.05$.

\subsection{Expatriate Sample}

The largest group of respondents $(48 \%)$ was in the age range of 36-46 years old, next (40\%) in the range of 25-35 years. This result is consistent with previous studies that indicate the average age of expatriates as upper $30^{\prime}$ and lower $40^{\prime}$ [20, 21]. The gender split was $85 \%$ male and $14 \%$ female, similar to other studies with foreign assignees [22]. Findings show that a constant share of women worldwide is about $20 \%$. The dominance of men can be explained by certain prejudices of foreigners towards women, secondly by lower willingness of companies to relocate women, and last but not least, lack of interest from women's prospect or their family reasons.

For most respondents of the survey $(62 \%)$ it was the first foreign assignment, in the following case $(28 \%)$ the second assignment. The largest group (38 cases) consisted of persons who were assigned abroad for the first time and at the same time of its beginning, only 3-6 months (due to the stipulated selection requirement for respondents already completed at least three months for posting). When aggregating the offered periods of assignments in the questionnaire, it can be argued that $41 \%$ of respondents had completed the period of up to one year at the time of answering the questionnaire.

Previous contact with the host culture can be considered an 
important prerequisite for the continued successful operation of foreign culture. As many as $39 \%$ of respondents have already encountered a foreign culture as part of their business trip, and $22 \%$ have taken advantage of the Pre-Assignment Trip, a multi-day trip to their future country of assignment. However, almost $16 \%$ of respondents had no previous contact with the host culture, which is an important finding to be considered in company's human resource department.

\subsection{Systematic Thinking Approach}

In order to develop the model of intercultural adaptation, systematic thinking approach has been chosen as appropriate method. The topic of mobility and intercultural management are considered to be a complex system in which human factor and individual characteristics play an important role in their formation and function.

People usually have a natural tendency to think linearly, which means that each consequence has its own cause and the development is linear. In contrast, systemic thinking is based on the fact that human behavior is often determined by emotions and instincts, not by rational decisions, which leads to inclination towards so-called behavioral approach of economics [23]. Moreover, using systemic thinking means perceiving matters in interaction with each other [24]. It emphasizes not only the links between the elements of the system and their backward dynamics but also the principle of circularity and dynamic equilibrium, and is therefore suitable for the creation of a targeted model.

\section{Findings}

\subsection{Adaptation}

The adaption level was assessed by respondents on the scale 1 to 7 , when $1=$ completely non-adapted and $7=$ completely adapted, in totally 11 variables. These variables displayed in Table 1 are classified into three subcategories:

1. Living environment - living conditions generally; accommodation conditions; food; shopping;

2. Host country mentality - developing personal relations and spending free time with locals; accepting of non-written rules of behaviour and cultural standards; everyday communication with locals;

3. Work environment - work environment generally; interaction with local colleagues; specific work requirements; performance standards and work expectations.

Table 1. Selected characteristics of distribution and variability for particular variables of adaptation.

\begin{tabular}{lll}
\hline Category & Arithmetic mean & Variance \\
\hline Living conditions & 5,65 & 1,09 \\
Accommodation conditions & 6,08 & 1,16 \\
Food & 5,92 & 1,32 \\
Shopping & 5,87 & 1,27 \\
Developing personal relations and spending free time with locals & 4,81 & 2,48 \\
Everyday communication with locals & 5,21 & 2,13 \\
Accepting of non-written rules of behaviour and cultural standards & 5,54 & 1,34 \\
Performance standards and work expectations & 5,78 & 1,13 \\
Interaction with colleagues & 5,76 & 1,27 \\
Work environment & 5,51 & 1,06 \\
Specific work requirements & 5,56 & 1,22 \\
\hline
\end{tabular}

Adaption in terms of host country mentality and developing of relations with local inhabitants proved to be the most difficult issue. Although the expatriate gets used to new environment consisting of the accommodation and different food offer, and despite his/her existence without bigger difficulties in the job, he/she does not really integrate into the host society.

First, the relationship between the level of language proficiency and selected aspects of adaptation were examined, namely the creation of personal relationships and leisure activities with the local population; interaction with colleagues and daily communication with the local population. As in other cases, the rate of survival was determined by a dependent variable. As the values in Table 2 show, the calculations confirmed the linear correlation of foreign language knowledge with the degree of adaptation in the interaction with colleagues. No correlation was found in two other areas of adaptation.

Table 2. Relationship between language proficiency and selected aspects of adaptation.

\begin{tabular}{ll}
\hline Category & Kendall coefficient \\
\hline Creating personal relationships and spending leisure time with the local population & 0,052 \\
Interaction with colleagues & 0,121 \\
Everyday communication with locals & 0,021 \\
\hline
\end{tabular}

Relation of dependency between intercultural training participation and the level of adaptation abroad was investigated as next objective. Linear correlation between intercultural training participation and variables of adaptation (as listed in Table 1) and therefore contribution of intercultural training was found positive specifically in terms of the adaptation on living conditions; accepting of non-written rules of behavior and cultural standards; and everyday communication with locals.

Another relationship examined was the effect of previous 
experiences with the host country (vacation, business trip, Pre-Assignment Trip, family reasons, educational stay), which were calculated as the sum (0-5), on the level of survival, again all eleven areas of adaptation. Based on the values given in Table 3, the above-mentioned relationship was proven in the case of interaction with local colleagues and everyday communication with the local population. The more an assigned individual has previous experience with the host culture, the easier it is to interact with local colleagues and communicate with the local people in general.

Table 3. Relation between previous past experiences with host culture and level of adaptation.

\begin{tabular}{lll}
\hline Category & Kruskal-Wallis test \\
\hline Living conditions & 7,891 \\
Accommodation conditions & 7,286 \\
Food & 9,019 \\
Shopping & 5,648 \\
Developing personal relations and spending free time with locals & 6,253 \\
Work environment & 4,706 \\
Interaction with colleagues & 8,171 \\
Accepting of non-written rules of behaviour and cultural standards & 3,340 \\
Specific work requirements & 5,308 \\
Performance standards and work expectations & 3,662 \\
Everyday communication with locals & 0,172 \\
\hline
\end{tabular}

\subsection{Motivation}

Within the assessment of the motivation level, respondents had a choice of a total of eight motivating factors: Career growth, Language skills development, Experience of a new country and culture, Personal development, Financial reward, Professional development, Family reasons and Others.

The most important motivational factor for outgoing employees was their development - whether personal or professional. That is followed by Language skills development and Experience of new country and culture, which only confirms the importance of the first two motives. The least motivating factor for a foreign assignment is Family Reasons, which could be contrary rather demotivating The factor Others which was offered if other factors were not sufficient, characterizes the modus of value 1 , as well as Family reasons but with a significantly lower variance, therefore it can be concluded that there is a minimum of other motivational factors. Financial reward is a factor determined by the salary and bonus policy of companies. Given that $62 \%$ of respondents were on first assignment, it is possible that they will not feel the effect of financial subsidies and benefits provided to them during stay abroad until they return.

Figure 1 displays the average motivation for motivational factors evaluated by the range 1-7, where 1 stands for no motivation and 7 means entirely motivating influence.

Attention should be paid to all factors that influence the motivation for working abroad. Family situation can be taken as a factor that might make the decision of departure more difficult, or even the whole adaptation process and hence the performance of an employee on assignment. For younger expatriates who do not yet have their own family or have children of pre-school age, the expatriation is easier. Professional development and Career growth have proven to be strong motives and the job title should always be clearly defined after repatriation.

The highly evaluated factor of Personal development shows that assigned employees realize the benefits of staying abroad and experiencing foreign culture for themselves. This result can also be correlated with the development of intercultural competences and the importance of intercultural training and language training, as further demonstrated by the Language skills development factor for motivating the departure for assignment.

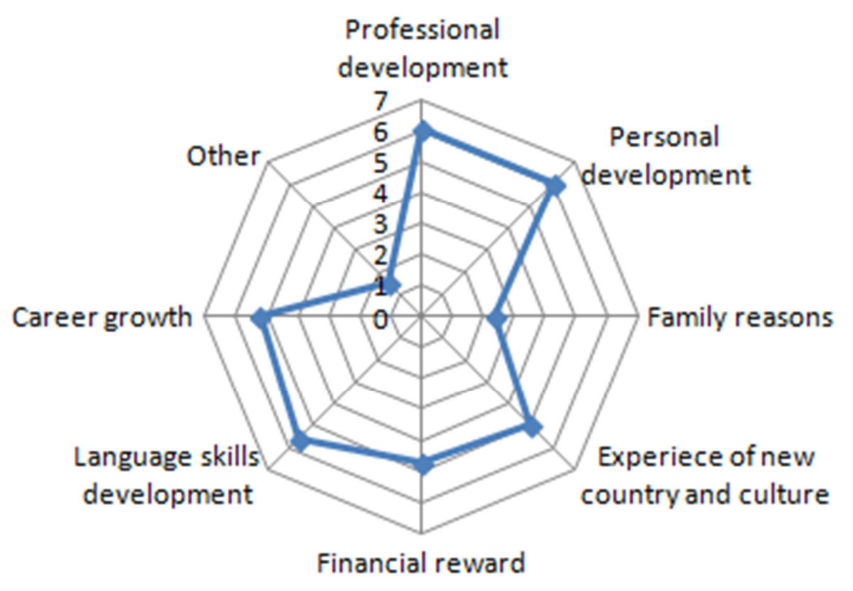

Figure 1. Average motivation.

\subsection{Model of Intercultural Adaptation}

The intercultural adaptation model captures the determinants of adaptation taking place in the intercultural environment and the individual relationships that exist between the variables. In total, six determinants have been defined on the basis of primary and secondary research:

1. Intercultural competence

2. Language skills

3. Intercultural training

4. Past intercultural experience

5. Motivation

6. Cultural distance

The model was processed in Vensim PLE x32 program and it is shown in Figure 2. The individual symbols used in the model illustration are explained in the note below. 


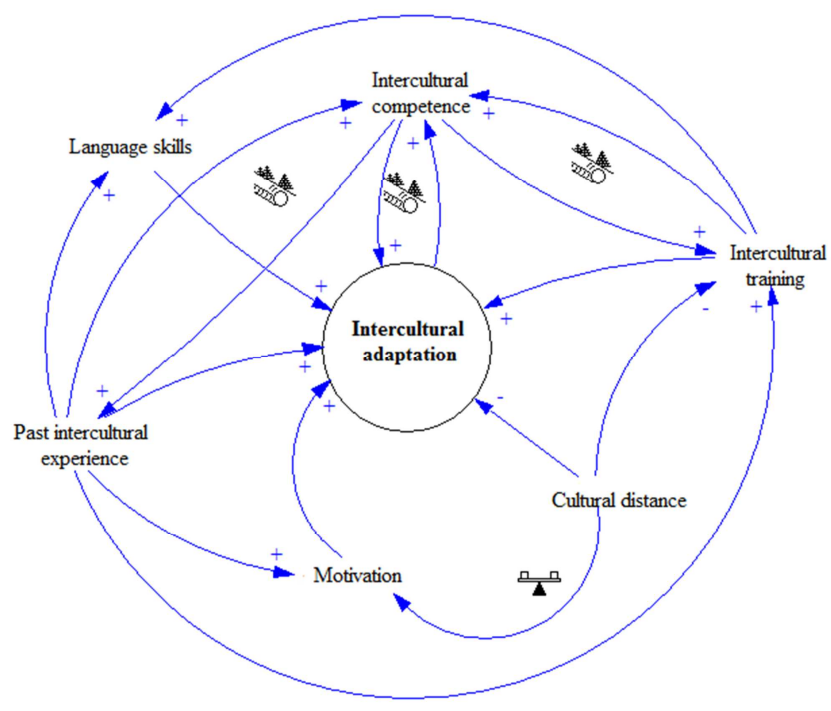

Figure 2. Model of intercultural adaptation ${ }^{l}$.

As is evident from the model, except of cultural distance, all other determinants have a positive impact on intercultural adaptation. Thus, for example, a higher level of intercultural training has a positive effect on intercultural adaptation. The same applies in another case, ie motivation - the higher the motivation to leave, the easier the course of adaptation abroad can be expected.

The mentioned cultural distance determinant has the opposite expected effect. The higher the cultural distance, the more difficult intercultural adaptation the expatriated individuals are exposed to. In addition, cultural distance has increased demands for intercultural training. Individual influence of cultural distance can be observed due to the motivation for the trip. High cultural distance can be an interesting motivating factor for someone; on the other hand, it can discourage someone and reduce motivation.

Positive backward force can be observed in three cases. Specifically between:

1. previous intercultural experience and intercultural competence;

2. intercultural competence and intercultural adaptation;

3. intercultural competence and intercultural training.

For explanation; previous intercultural experience has a positive impact on intercultural competences and it even develops it to a higher level. Similarly, the level of intercultural competences, which also stands before the very previous intercultural experience, has an impact on the experience of the intercultural experience. The same situation also applies to intercultural competences whose level affects the course and benefits of intercultural training. Simultaneously, intercultural training positively affects intercultural competences.

\footnotetext{
${ }^{1}$ Symbol on arrow + (plus): first variable causes a change in second variable in the same direction (positive influence); symbol on arrow - (minus): first variable causes a change in second variable in the opposite direction (negative influence); a positive backward relation; $\frac{1}{\boldsymbol{T}}$ individual dependent, positive and negative backward relation.
}

Finally, we can generally state that the determinants influencing intercultural adaptation, and therefore the success or failure of an expatriate, can be classified as:

1. individual;

2. organizational / systemic and

3. environmental.

None of the determinants exists separately from the others; the above mentioned classifications are interconnected as well as the individual variables.

Although a large number of intercultural adaptation models in cross-cultural studies can be found, the depiction of linkages between variables based on a systemic thinking approach makes the presented model of intercultural adaptation unique.

\section{Conclusion}

The internationalization of the company is nowadays a natural stage of the company's development. At the same time, the internationalization of human resources, manifested not only by the employment of foreign experts, but also by the international enterprise mobility of the workforce, can be perceived as a key element of competitiveness and a positive factor of performance.

Employee adaptation is not a simple matter, as it takes place under various factors and cannot be done by applying a single template. Companies have different organizational cultures and in a multicultural work environment it is especially necessary to take into account the different needs of all shareholders, managers and individual employees. It is also necessary to consider whether adaptation in such a different environment will be aimed at the majority or minority of employees, or if it is a compromise on both sides. Another question is how far the adaptation process will be carried out and what areas it will address.

The paper investigates the international experience of Czech expatriates and based on data obtained via questionnaire the determinants of intercultural adaptation of were stated. Determinants congregated from primary and secondary research of previous studies were used for development of the model of intercultural adaptation. Due to the systematic thinking approach that was applied, the model illustrates links between the determinants as positive or negative influences between each other.

The article points out the importance of deeper understanding of the adaptation process complexity. It is necessary to realize that poor adaptation of an expatriate often leads to failure of the assignment which is very costly for a sending company. To master a selection process of suitable candidate for foreign assignment in order to minimize the risk of failure and secondly, to employ effective intercultural training are crucial steps that the company and its human resource department must consider. 


\section{References}

[1] J. W. Berry, et al., "Cross-cultural psychology," 2nd ed. Cambridge: Cambridge University Press, 2002. ISBN 978-0-521-64617-8.

[2] G. M. Chen, "Theorizing intercultural adaptation from the perspective of boundary game," in China Media Research, 2013, vol. 9, no. 1, pp. 1-10. ISSN 1556-889X.

[3] G. Cui, "Measuring intercultural effectiveness: An integrative approach," in International Journal of Intercultural Relations, 1992, vol. 16, no. 3, pp. 311-328. ISSN 0147-1767.

[4] S. Lysgaard, "Adjustment in a foreign society. Norwegian Fulbright grantees visiting the United States," in International Social Sciences Bulletin, 1955, vol. 7, pp. 45-51. ISSN 1012-9537. DOI: 10.1111/j.1540-4560.1956.tb00372.x.

[5] J. Zhu, C. R. Wanberg, D. A. Harrison, and E. W. Diehn, "Ups and downs of the expatriate experience? Understanding work adjustment trajectories and career outcomes," in Journal of Applied Psychology, 2016, vol. 101, no. 4, pp. 549.

[6] K. Bierwiaczonek, and S. Waldzus, "Socio-cultural factors as antecedents of cross-cultural adaptation in expatriates, international students, and migrants: A review. " in Journal of Cross-Cultural Psychology, 2016, vol. 47, no. 6, pp. 767-817.

[7] G. Hofstede, J. Hofstede, and M. Minkov, "Cultures and Organizations: Software of the Mind." Revised and expanded 3rd ed., McGraw-Hill Education, 2010. ISBN007166418.

[8] J. Knocke, J., and T. Schuster, "Repatriation of international assignees: Where are we and where do we go from here? A systematic literature review. " in Journal of Global Mobility, 2016, vol. 5, no. 3, pp. 275-303.

[9] M. Morgensternová, and L. Šulová, "Interkulturní psychologie: rozvoj interkulturní sensitivity,” Praha: Karolinum, 2007. ISBN 9788024613611.

[10] K. F. Gaw, "Reverse culture shock in students returning from overseas," in International Journal of Intercultural Relations, 2000, vol. 24, no. 1, pp. 83-104. ISSN 0147-1767.

[11] N. J. Adler, and A. Gundersen, "International dimensions of organizational behavior," 5th ed., Cengage Learning, 2007. ISBN 978-0-324-36074-5.

[12] R. Čuhlová, and M. I. Yar, “ Role of intercultural training in a process of human resource internationalization," in Acta Academica Karviniensia, 2018, vol. 18, no. 3, pp. 15-26.
[13] K. A. Demes, and N. Geeraert, "Measures matter: Scales for adaptation, cultural distance, and acculturation orientation revisited," in Journal of Cross-Cultural Psychology, 2014, vol. 45, no. 1, pp. 91-109.

[14] R. Cuhlová, "Cultural distance of foreign investors in the Czech Republic based on Hofstede's dimensions," in Ad Alta: Journal of Interdisciplinary Research, 2016, vol. 1, no. 6, pp. 14-17. ISSN 1804-7890.

[15] R. L. Pope, and A. L. Reynolds, "Student affairs core competencies: Integrating multicultural awareness, knowledge, and skills," in Journal of College Student Development, 1997, vol. 38, no. 3, pp. 266-277. ISSN 1543-3382.

[16] A. K. Gupta, and V. Govindarajan, "Building an effective global business team," in MIT Sloan Management Review, 2001, vol. 42, no. 4, pp. 63-71. ISSN 1532-9194.

[17] J. Richardson, and S. McKenna, "Leaving and experiencing: why academics expatriate and how they experience expatriation." in Career Development International, 2002, vol. 7, no. 2, pp. 67-78. ISSN1362-0436.

[18] I. Brooks, "Organizational Behaviour: Individuals, Groups and Organization," Essex: Pearson Education Limited, 2006. ISBN 9780273715368 .

[19] D. C. Thomas, and M. B. Lazarová, "Expatriate adjustment and performance: a critical review," in G. Stahl, and I. Bjorkman (eds.), "Handbook of Research In International Human Resource Management," Edward Elgar Publishing, Cheltenham, 2006, pp. 247-264. ISBN 1845421280.

[20] C. C. Bright, "Investigating the relationship between expatriate adjustment, marital status, and related attributes," University of Phoenix, ProQuest Dissertations Publishing, 2008, 3364166.

[21] R. Shmueli, S. L. Dolan and J. L. Cerdin, "Emotional intelligence as predictor of cultural adjustment for success in global assignments," in Career Development International, 2005, vol. 10, no. 5, pp. 375-395. ISSN 1362-0436.

[22] S. Shortland, "The purpose of expatriation: why women undertake international assignments," in Human Resource Management, 2016, vol. 55, no. 4, pp. 655-678.

[23] S. Mildeová, et al., "Tvorba manažerských simulátorů: vaše virtuální firma." Oeconomica, Praha, 2007. ISBN 978-80-245-1286-0.

[24] Z. Molnár, S. Milderová, H. Řezanková, R. Rixí, and J. Kalina, "Pokročilé metody vědecké práce," 1. ed. Praha: Profess Consulting, 2012. ISBN 978-80-7259-064-3. 